\title{
A new space-borne perspective of crop productivity variations over the US Corn Belt
}

Article

Published Version

Creative Commons: Attribution 4.0 (CC-BY)

Open Access

Somkuti, P., Boesch, H., Feng, L., Palmer, P. I., Parker, R. J. and Quaife, T. (2020) A new space-borne perspective of crop productivity variations over the US Corn Belt. Agricultural and Forest Meteorology, 281. 107826. ISSN 0168-1923 doi: https://doi.org/10.1016/j.agrformet.2019.107826 Available at https://centaur.reading.ac.uk/87016/

It is advisable to refer to the publisher's version if you intend to cite from the work. See Guidance on citing.

To link to this article DOI: http://dx.doi.org/10.1016/j.agrformet.2019.107826

Publisher: Elsevier

All outputs in CentAUR are protected by Intellectual Property Rights law, including copyright law. Copyright and IPR is retained by the creators or other copyright holders. Terms and conditions for use of this material are defined in the End User Agreement.

www.reading.ac.uk/centaur 
Central Archive at the University of Reading

Reading's research outputs online 


\title{
A new space-borne perspective of crop productivity variations over the US Corn Belt
}

\author{
Peter Somkuti*,1,a,b ${ }^{\text {, Hartmut Bösch }}{ }^{\mathrm{a}, \mathrm{b}}$, Liang Feng ${ }^{\mathrm{c}, \mathrm{d}}$, Paul I. Palmer ${ }^{\mathrm{c}, \mathrm{d}}$, Robert J. Parker ${ }^{\mathrm{a}, \mathrm{b}}$, \\ Tristan Quaife ${ }^{\mathrm{e}, \mathrm{f}}$ \\ ${ }^{a}$ School of Physics and Astronomy, University of Leicester, Leicester, UK \\ ${ }^{\mathrm{b}}$ National Centre for Earth Observation, University of Leicester, Leicester, UK \\ ${ }^{\mathrm{c}}$ School of GeoSciences, University of Edinburgh, Edinburgh, UK \\ ${ }^{\mathrm{d}}$ National Centre for Earth Observation, University of Edinburgh, Edinburgh, UK \\ ${ }^{\mathrm{e}}$ Department of Meteorology, University of Reading, Reading, UK \\ ${ }^{\mathrm{f}}$ National Centre for Earth Observation, University of Reading, Reading, UK
}

\section{A R T I C L E I N F O}

\section{Keywords:}

Fluorescence

Crops

Yield

GOSAT;

\begin{abstract}
A B S T R A C T
Remotely-sensed solar-induced chlorophyll fluorescence (SIF) provides a means to assess vegetation productivity in a more direct way than via the greenness of leaves. SIF is produced by plants alongside photosynthesis so it is generally thought to provide a more direct probe of plant status. We analyze inter-annual variations of SIF over the US Corn Belt using a seven-year time series (2010-2016) retrieved from measurements of short-wave IR radiation collected by the Japanese Greenhouse gases Observing SATellite (GOSAT). Using survey data and annual reports from the US Department of Agriculture (USDA) National Agricultural Statistics Service (NASS), we relate anomalies in the GOSAT SIF time series to meteorological and climatic events that affected planting or growing seasons. The events described in the USDA annual reports are confirmed using remote sensing-based data such as land surface temperature, precipitation, water storage anomalies and soil moisture. These datasets were carefully collocated with the GOSAT footprints on a sub-pixel basis to remove any effect that could occur due to different sampling. We find that cumulative SIF, integrated from April to June, tracks the planting progress established in the first half of the planting season (Pearson correlation $r>0.89$ ). Similarly, we show that crop yields for corn (maize) and soybeans are equally well correlated to the integrated SIF from July to October $(r>0.86)$. Our results for SIF are consistent with reflectance-based vegetation indices, that have a longer established history of crop monitoring. Despite GOSAT's sparse sampling, we were able to show the potential for using satellite-based SIF to study agriculturally-managed vegetation.
\end{abstract}

\section{Introduction}

The US Corn Belt is a major agricultural region and of great importance to US food security, the US livestock industry, and, through sales of agricultural products alone, contributes on the order of $\$ 134 \mathrm{bn}$ (about a third of the US total agricultural sales) to the US GDP (USDA, 2019a). It is vital that changes in the characteristics of this region, driven by changes in climate or agricultural and land use practices, can be readily and routinely monitored. Satellite observations allow large-scale regional assessment of factors such as crop yield, with chlorophyll fluorescence having previously been shown to act as a more sensitive indicator of water stress compared to greenness indices (Lee et al., 2013). In the future, applying such techniques to the US
Corn Belt could provide additional means to characterize growing periods and crop yields.

Geographically, the Corn Belt is located in the midwestern United States, and while there is no widely accepted and unique definition of the area, it roughly encompasses parts of Minnesota (MN), North Dakota (ND), South Dakota (SD) and Nebraska (NE), most of Iowa (IA), Illinois (IL) and Indiana (IN), as well as Ohio (OH), Kansas (KS) and Missouri (MO). The name stems from the fact that corn (maize) is the most prevalent crop in that region, and that it is the source of over a third of the world's corn and soybean production (Grassini et al., 2015; Green et al., 2018).

One main aspect differentiates the Corn Belt from other ecosystems of similar size: as a result of the intense agricultural use of mainly corn

\footnotetext{
* Corresponding author.

E-mail address: peter.somkuti@colostate.edu (P. Somkuti).

${ }^{1}$ Corresponding author, now at Colorado State University
} 
and soybeans, the region is not only a potential net carbon sink (Lauvaux et al., 2012; Twine and Kucharik, 2009), its seasonality is strongly influenced by agricultural practices. Planting and harvesting times can shift depending on meteorological conditions that are counter-intuitive to natural ecosystems - spring rainfall, for example, can delay planting progress, while in water-limited natural ecosystems it might cause an early growth onset.

Studies on the Corn Belt using remote sensing have utilized mostly imaging-type instruments, such as MODIS. Many studies focus on the mapping of crops (Zhong et al., 2016) and the change in agricultural use of land (Arora and Wolter, 2018), monitoring growing conditions and droughts (Liu et al., 2018; Wu et al., 2015) and crop yield predictions (Johnson, 2014).

A relatively new remote sensing product is solar-induced chlorophyll fluorescence (SIF). SIF is a weak radiation signal in the far-red wavelength range between $650 \mathrm{~nm}$ and $800 \mathrm{~nm}$ that is emitted by plants while they perform photosynthesis. This radiance signal is directly linked to the photosynthetic apparatus of the plant and is thus seen as a more direct probe of carbon fixation than, for example, reflectance-based measurements; see Meroni et al. (2009) for a detailed overview. Remote sensing of SIF on a global scale has been possible since the advent of hyperspectral, space-based measurements of the oxygen $\left(\mathrm{O}_{2}\right)$ A-band near $760 \mathrm{~nm}$. These remotely sensed data products were pioneered by Joiner et al. (2011) and Frankenberg et al. (2011), who showed that a global and consistent picture can be obtained from the high spectrally resolved GOSAT/TANSO-FTS instrument. The methodology has since then been applied to other space-based instruments, such as GOME-2 and SCIAMACHY (Joiner et al., 2013; Köhler et al., 2015), OCO-2 (Sun et al., 2018) and most recently TROPOMI (Köhler et al., 2018).

The utility of remotely-sensed SIF was explored early on. Lee et al. (2013) found in a study over the Amazonia region that SIF performs better as a predictor for water stress than the reflectancebased enhanced vegetation index (EVI). Guanter et al. (2014) found that global patterns and trends of SIF agree well with gross primary production (GPP) estimates from process-based and data-driven carbon cycle models. On a more regional scale, Sun et al. (2015) discuss the response of SIF to two drought events in the US. Here, we construct a multi-satellite perspective on the US Corn Belt in the 2010 to 2016 time period, focusing especially on the SIF record and its relationship to agricultural data.

\section{Materials \& methods}

\subsection{Solar-induced fluorescence from GOSAT}

GOSAT is the first mission solely dedicated to the accurate measurement of atmospheric concentrations of carbon dioxide $\left(\mathrm{CO}_{2}\right)$ and methane $\left(\mathrm{CH}_{4}\right)$. Launched in early 2009 and operated by the Japan Aerospace Exploration Agency (JAXA), the Japanese Ministry of Environment (MoE) and the National Institute for Environmental Studies (NIES), GOSAT employs a Fourier-Transform Spectrometer (TANSO-FTS) to passively measure sunlight back-reflected from the surface of the Earth (Yokota et al., 2009). GOSAT/TANSO-FTS measures in three bands in the near-infrared (NIR) and shortwave infra-red (SWIR) wavelength regions, as well as one additional band in the thermal infra-red (TIR). These hyper-spectral measurements are then used together with appropriate physical models and inversion schemes to retrieve the atmospheric concentration of the trace gases.

For the retrieval of SIF, we exclusively use band 1, the $\mathrm{O}_{2}$ A-band, which is located near $760 \mathrm{~nm}$. Band 1 features high spectral resolution at $0.5 \mathrm{~cm}^{-1}$ or $\approx 0.03 \mathrm{~nm}$, such that several solar (Fraunhofer) lines are resolved and can thus be utilized for the retrieval of SIF. We use the retrieval method described in Frankenberg et al. (2011). This so-called physically-based retrieval is derived from the Fraunhofer line discrimination method, first described in Plascyk (1975). Briefly summarized, the method relies on the fact that any additive radiation originating from the surface will reduce the fractional depth of Fraunhofer lines in the top of atmosphere (TOA) spectrum. It is therefore possible to decouple reflectance from the additive fluorescence contribution to the total TOA radiance. TANSO-FTS records radiances in the near-visible to shortwave infrared wavelength range in two linear polarization states: P - parallel, and S - perpendicular to the sensor plane, spanned between the radial Earth-spacecraft vector, the spacecraft velocity vector, and the vector between spacecraft yaw and spacecraft velocity.

To perform the GOSAT SIF retrievals, we employ the University of Leicester Full-Physics algorithm (Cogan et al., 2012), called UoL-FP. It derives atmospheric and surface quantities from hyper-spectral measurements via its two components: a full-physics forward model, which accurately models the solar radiation entering and propagating through Earth's atmosphere and its interaction with the surface, and the finite response at the detector on the space-based platform. The forward model calculations are then coupled with the second component of the algorithm: a non-linear inversion scheme that applies the LevenbergMarquardt modification to the Gauss-Newton method, in order to modify certain input parameters of the forward model (the so-called state vector) to match model calculation with real measurements. Inferring atmospheric and surface quantities as well as quantifying the uncertainty on each retrieved parameter is performed using a Bayesian optimal estimation (OE) framework (Rodgers, 2000).

We make use of the same processing pipeline which was previously used for the generation of high-quality atmospheric trace gas data sets (e.g. Buchwitz et al., 2017; Trent et al., 2018) at the University of Leicester, using the same core retrieval algorithm. On a per-scene (measurement) basis, the surface pressure is informed by the ECMWF ERA-Interim model, and the surface albedo is estimated through the measured radiances themselves assuming a Lambertian surface model.

We retrieve SIF at two micro-windows at $755 \mathrm{~nm}$ $(755.86-758.95 \mathrm{~nm})$ and $772 \mathrm{~nm}(769.59-774.83 \mathrm{~nm})$, as well as the two polarizations, independently, using the method of Frankenberg et al. (2011). For both retrieval windows, the SIF radiances are represented by a constant additive offset to the TOA radiances, along with a linear surface albedo (constant + slope), and instrument dispersion shift and stretch. As there are weak oxygen lines present in the $772 \mathrm{~nm}$ window, surface pressure is additionally retrieved in that micro-window. We exclude any scenes with large cloud contamination by using a cloud-screening algorithm beforehand. Only those GOSAT scenes are processed where the apparent surface pressure deviated by less than $100 \mathrm{hPa}$ from the ECMWF ERA-Interim prediction. The comparatively large surface pressure deviation threshold is possible due to SIF retrievals being less sensitive to cloud contamination of the scene (Frankenberg et al., 2012).

A crucial step in the SIF retrieval process is the bias correction. Small non-linearities introduced by the analog-to-digital conversion of the TANSO-FTS interferograms can result in similar errors in the Fraunhofer lines, and thus lead to unrealistic SIF values. In order to rid the measurements of these instrument artefacts, the retrieved SIF values need to be corrected. To achieve the bias correction, we use a slightly different method compared to Frankenberg et al. (2011). First, we use the ESA CCI Land Cover map v2.0.7 (Bontemps et al., 2013) to obtain the land cover classes for the surfaces seen by each GOSAT measurement (see Section 2.5). To identify footprints which can be assumed to be permanently free of vegetation, we consider only surfaces where at least $95 \%$ of all land cover-class pixels within the footprint belong to the types: urban, desert, snow and ice, or any bare type. This approach has the advantage that highly reflective surfaces like ice shields or deserts are used for the correction process, as well as darker surfaces such as mountainous regions.

We produce calibration curves via the relationship between retrieved offset and the mean radiance in the entire first GOSAT band. Ideally, this curve would be flat and centered around zero, however the 
instrumental artefacts lead to a somewhat complicated shape - see e.g. Frankenberg et al. (2011) supplementary materials, or Guanter et al. (2012) Appendix A. This instrumental bias varies over time and requires a time-dependent correction. Consequently, we use three different strategies to correct for this instrumental bias. For the first one, we collect retrievals over non-fluorescing areas in seasonal aggregates (DJF, MAM, JJA, SON). For every season in every year, we correct the SIF retrievals according to the calibration curve derived for that particular season-year combination. The second strategy is similar, the only difference being that retrievals for an entire year are collected. The main difference in the two methods is the aggregation period: shorter periods make the calibration curves noisy, however are better able to identify instrument issues that result in bias. The third and most elaborate strategy takes the time-dependence more explicitly into account. All retrievals over non-fluorescing areas are collected and binned two dimensionally: monthly bins for the time dimension, and 14 bins in the radiance dimension. Through this regular 2D grid, a spline interpolation function is used to calculate the bias at any given point in timeradiance space.

To summarize, we have a set of six SIF time series: using GOSAT measurements of two linear polarizations, and corrected using three different aggregation lengths. We have not identified one or more of these time series to be preferable over the others, and thus treat all of them as equally valid.

\subsection{Carbon fluxes from inversion of GOSAT $\mathrm{XCO}_{2}$}

The primary objective of the GOSAT mission is to constrain subcontinental-scale surface carbon fluxes. This is achieved through the inversion of atmospheric transport models in combination with accurate measurements of atmospheric $\mathrm{CO}_{2}$. Hyperspectral measurements from TANSO-FTS are converted into column-averaged dry-air mole fractions $\left(\mathrm{XCO}_{2}\right)$ using a retrieval algorithm that is described in detail in Cogan et al. (2012). Surface fluxes can then be obtained using this GOSAT-based $\mathrm{XCO}_{2}$ by coupling an atmospheric transport model with an inversion scheme. Since space-based platforms can provide global sampling, these measurements have the potential to improve on the global carbon flux picture complement to in-situ surface flux measurements (Chevallier et al., 2009; Rayner and O'Brien, 2001).

We compare the SIF data with a posteriori $\mathrm{CO}_{2}$ surface fluxes within the region of interest (ROI) that were inferred from the GOSAT $\mathrm{XCO}_{2}$ v7.1 product from the University of Leicester (Buchwitz et al., 2018) using the GEOS-Chem atmospheric transport model and an ensemble Kalman filter (Feng et al., 2016; Palmer et al., 2019). In the inversion, we use the v9.02 GEOS-Chem global chemistry transport model (http:// acmg.seas.harvard.edu/geos/index.html) to relate a priori surface fluxes (and their uncertainty) to atmospheric $\mathrm{CO} 2$ observations. We run the model at a spatial resolution of $4^{\circ}$ (latitude) by $5^{\circ}$ (longitude) with 47 vertical levels, driven by GEOS-5 (2009-2012) and GEOS-FP (2013-2016) meteorological analyses from the Global Modeling and Assimilation Office at NASA Goddard Space Flight Centre. We use a priori flux inventories to describe: monthly fossil fuel emissions (Oda and Maksyutov, 2011); weekly biomass burning emissions (van der Werf et al., 2010); climatological monthly oceanic surface fluxes (Takahashi et al., 2009), and three-hourly net terrestrial biosphere-atmosphere fluxes (i.e., NEE) from the CASA model (Olsen and Randerson, 2004). We then infer posterior fluxes by optimally fitting the model simulations with GOSAT $\mathrm{XCO}_{2}$ retrievals (Feng et al., 2009). For further information on our inversion setup, the reader is referred to Feng et al. (2016) and Palmer et al. (2019).

Since the total surface carbon fluxes in the region of interest are dominated by contributions from the $\mathrm{CO}_{2}$ fixation part of photosynthesis as well as plant respiration, its variation will be directly reflected in SIF anomalies.

\subsection{Agricultural statistics from the united states department for agriculture}

To help interpret the various SIF anomalies given in Section 3.1, we use the crop summary reports published by the United States Department for Agriculture (USDA) National Agricultural Statistics Service (NASS). These reports are released annually and contain, amongst other items, overview statistics on crop planting area and harvest yield for a given year. They also provide a succinct overview of the climate conditions from planting to harvest and highlight meteorological events and their impacts on agriculture. The second USDA-NASS resource used here is the crop survey database (accessed online at https://www.nass. usda.gov/), which collects farmer survey data that tracks overall planting progress on a weekly basis at varying levels of spatial aggregation (we use per-state data).

\subsection{GOSAT sampling and region of interest}

As mentioned during the discussion on GOSAT SIF retrievals (Section 2.1), the FTS instrument, causes potential sampling biases due to the pointing locations as a result of the sampling strategy. While there is an inherent bias due to clouds, as GOSAT SIF retrievals cannot be performed in the presence of thick clouds, the sampling strategy results in non-uniform selection of surfaces throughout the region of interest (ROI) which covers the US states North Dakota (ND), South Dakota (SD), Kansas (KS), Nebraska (NE), Minneapolis (MN), Iowa (IA), Missouri (MO), Wisconsin (WI) and Illinois (IL). Fig. 1 shows the sampling density for the entire time period from the beginning of 2010 until the end of 2016 .

The question arises, whether the sampling of the various surfaces of the chosen ROI is representative of the entire area. To that end, we compare the most common land cover classes (Fig. 1 left) of the entire region of interest at the native resolution $(300 \mathrm{~m})$ of the ESA CCI Land Cover data set (excluding water bodies) to the sub-pixel aggregated data at the location of the GOSAT footprints. The result of the relative occurrence of the six most common types is shown in Fig. 2.

More than $75 \%$ of surfaces belong to either rainfed cropland or grassland types. The third most common surface type (deciduous tree cover) is mainly due to Ozark National Forest in Missouri, Superior National Forest as well as forests in northern Wisconsin. For the total period, GOSAT is representative of the overall composition of land cover classes of the region of interest. The largest differences are seen for flooded tree cover, where GOSAT is slightly over-representing $(+1.7 \%)$, and grassland, where GOSAT is under-representing $(-3.3 \%)$.

Repeating the same analysis on a monthly basis, a different picture than Fig. 2 can arise, as GOSAT's sampling is not only non-uniform geographically, but also changes over time. In Fig. 3, the differences between GOSAT-seen and total ROI land cover class coverage for
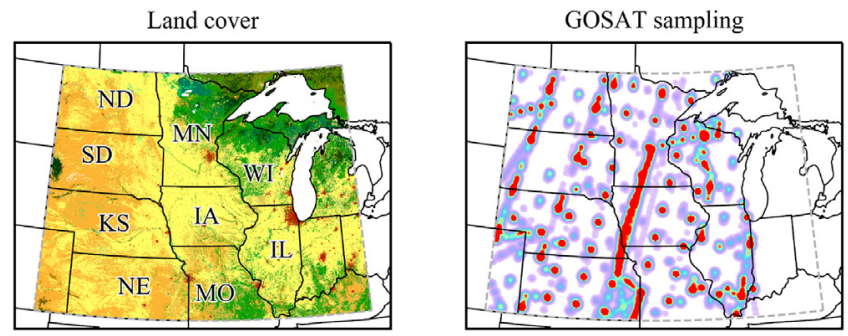

Fig. 1. Land cover classes (left) and GOSAT sampling density (right) shown for the region of interest (104W - 87.5W, 37N - 49N). Yellow land cover pixels correspond to crop, orange represents grassland, green-colored pixels are various tree types, and red areas are urban regions. In the right panel, all GOSAT soundings for the study period 2010 - 2016 are collected and visualized as a density map (red indicates higher sounding density) to illustrate the both sparse and irregular sampling pattern. (For interpretation of the references to colour in this figure legend, the reader is referred to the web version of this article.) 


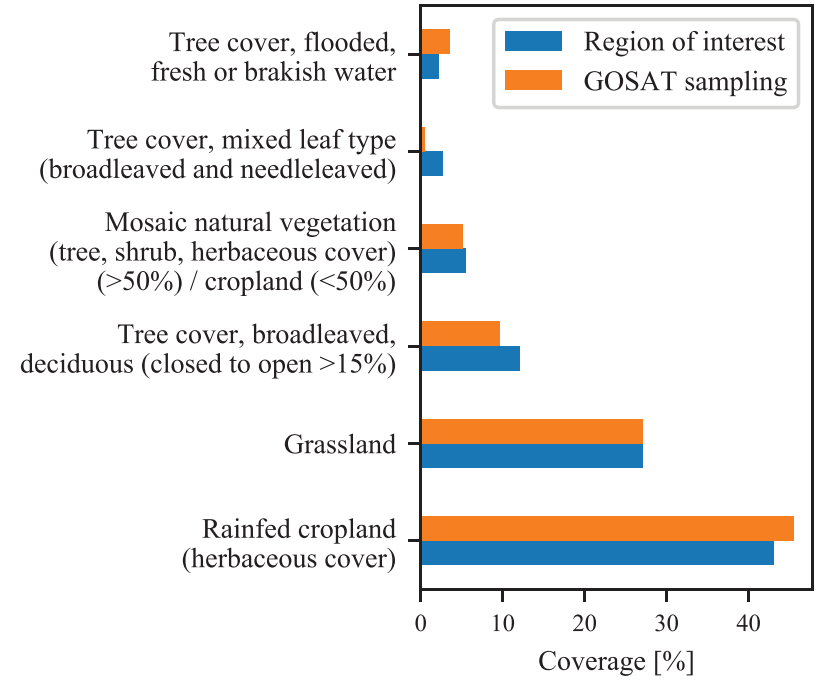

Fig. 2. A comparison of overall land cover coverage between the entire ROI and GOSAT sampling. This confirms that the sparse GOSAT sampling pattern wellrepresents the surface types within the ROI.

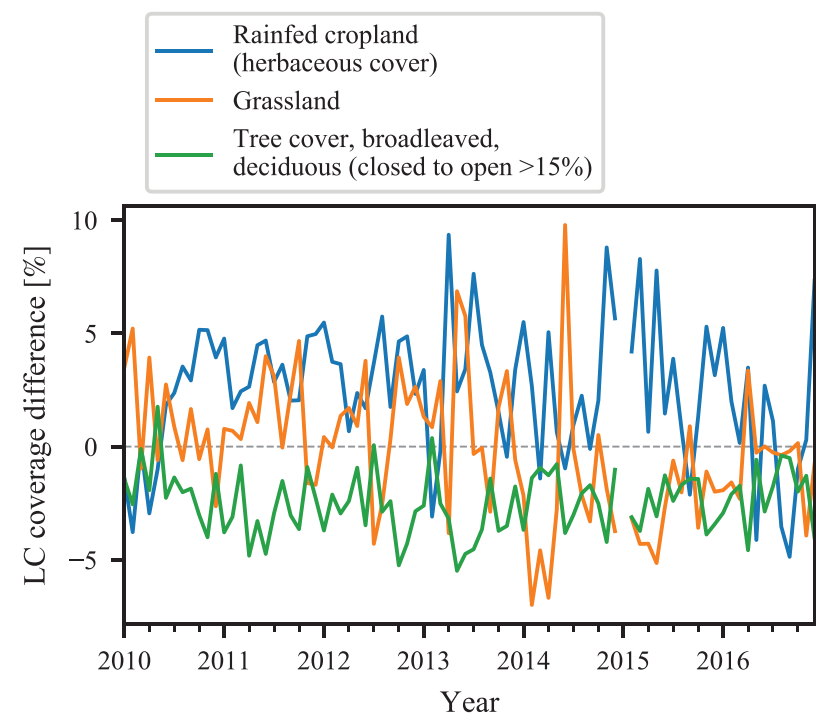

Fig. 3. The monthly differences between land cover coverage of the entire ROI and the land cover coverage as seen by GOSAT. January 2015 has not been taken into account due to the low number of measurements in that month.

monthly aggregates is shown for the three most prevalent classes.

It is worth noting that the land cover data itself contains uncertainties and for classes that are spectrally similar this will lead to negatively correlated errors in the reported areas especially where they co-exist in a complex mosaic (Quaife and Cripps, 2016).

We observe that differences can reach $10 \%$ for certain months. Months in which the differences are fairly large for cropland and grassland land cover types are: 2013/Apr, 2014/Feb, 2014/Mar, 2014/ Apr, 2014/Nov, 2015/Feb, 2015/Apr and 2016/Aug. Due to the careful handling of the EO data set sampling, the difference in land cover coverage should not have a significant impact on the further analysis and results. It is also important to note that while Figs. 2 and 3 confirm that the land cover classes are more or less well represented, vegetation responses can vary geographically over the Corn Belt, even though they might share the same land cover classification. Geographically varying differences in planting dates can lead to crops maturing at different times and thus dilute the ROI-averaged vegetation signals picked up via remote sensing.

As we are interested mainly in the response of crops (corn, soy), only GOSAT measurements that cover at least $50 \%$ of any cropland-type surface were kept for the subsequent analysis, and we use the SIF retrievals at $755 \mathrm{~nm}$.

\subsection{Spatially and temporally collocated earth observation data}

GOSAT/TANSO-FTS was designed to measure atmospheric trace gas concentrations through a point-sampling strategy, and thus differs from imaging-type measurement concepts, such as the MODIS instruments. The high-resolution spectrometer points at one location at a time with an instantaneous field of view (IFOV) of $15.8 \mathrm{mrad}$, which corresponds roughly to a circular footprint with $10.5 \mathrm{~km}$ diameter at nadir viewing geometry. As a consequence, it is necessary to consider the specific sampling pattern for the data sets in the analysis in order to avoid sampling bias (see Section 2.4).

For every GOSAT scene, we consider the full footprint as defined by the four extremal points of the footprint ellipse (as given in the L1B data). The sampled Earth observation datasets are listed in Table 1.

For collocation of the enhanced vegetation index (EVI), normalized differential vegetation index (NDVI), ESA CCI Land Cover, fractional vegetation cover (FVC) and leaf area index (LAI) datasets, the scenespecific GOSAT footprint is fully taken into account. Only those pixels, whose pixel area overlaps by at least $50 \%$ with the GOSAT footprint are aggregated to the scene-specific value. Soil moisture and TRMM/TPMA precipitation data, however, are of lower resolution where sub-pixel aggregation is not required. For TRMM/TPMA, the grid box is taken in which the GOSAT footprint lies, and for the soil moisture data (which is supplied on grid points rather than grid boxes), bi-linear interpolation of the closest four grid points is used. In the time dimension, linear interpolation is used for all data sets except for land cover data (annual), TRMM/TPMA precipitation and GRACE data (both monthly).

Table 1

Satellite-based earth observation datasets that we sampled at the specific GOSAT footprint locations. Land cover, fractional vegetation cover (FVC), leaf area index (LAI), normaized differential vegetation index (NDVI) and enhanced vegetation index (EVI) were sampled using sub-pixel matching. Precipitation (TRMM/TPMA) and GRACE were sampled at grid-box level, and for soil moisture we used linear interpolation between the nearest grid points.

\begin{tabular}{|c|c|c|c|}
\hline Dataset & Resolution & Range & Reference \\
\hline ESA CCI Land Cover v2.0.7 & $300 \mathrm{~m}$ & $2010-15$ & Bontemps et al. (2013) \\
\hline ESA CCI Soil Moisture v3.2 & $0.25^{\circ}$ & 2010-15 & Dorigo et al. (2017) \\
\hline MODIS/Aqua MYD13C1 V006 VI & $0.05^{\circ}$ & 2010-16 & Didan (2015) \\
\hline MODIS/Aqua MYD11C2 V006 LST & $0.05^{\circ}$ & $2010-16$ & Wan (2015) \\
\hline SPOT/VGT LAI V2.0.1 & $1 \mathrm{~km}$ & $2010-16$ & Maisongrande et al. (2004) \\
\hline POT/VGT FVC V2.0.1 & $1 \mathrm{~km}$ & $2010-16$ & Maisongrande et al. (2004) \\
\hline TRMM/TPMA 3B43 precipitation & $0.25^{\circ}$ & $2010-16$ & Huffman et al. (2007) \\
\hline GRACE liquid water equivalent thickness & $1^{\circ}$ & $2010-16$ & Landerer and Swenson (2012) \\
\hline
\end{tabular}




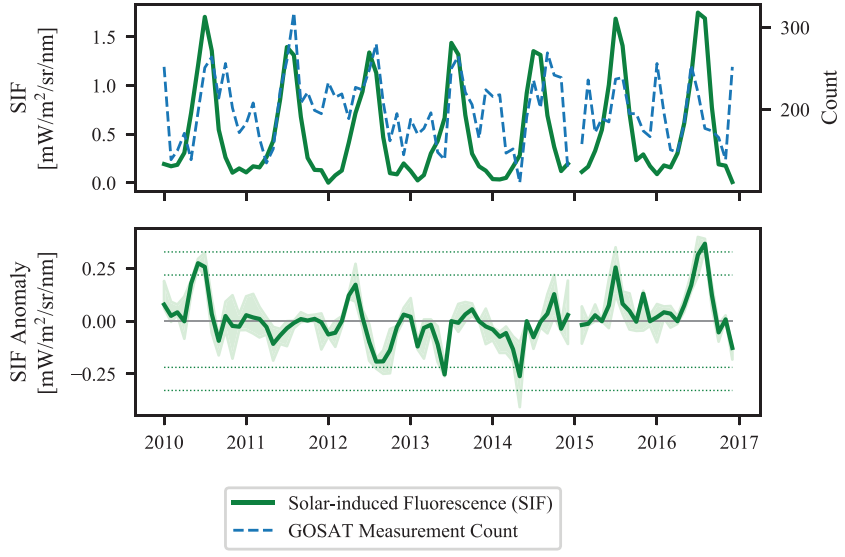

Fig. 4. The SIF time series (top panel) and corresponding anomaly plot (bottom panel). In the top panel, the green line represents the median of the six monthly-averaged SIF time series (two polarization states, three bias correction schemes), while the blue-dashed line represents the measurement count per month. The dotted lines in the bottom plot mark the $\pm 2 \sigma$ and $\pm 3 \sigma$ values of the anomalies, and the shaded area is bounded by the lowest and largest value of the six SIF time series. (For interpretation of the references to colour in this figure legend, the reader is referred to the web version of this article.)

\section{Results}

\subsection{SIF time series and anomalies between 2010 and 2016}

The SIF retrievals are aggregated on a monthly basis, where the mean of all measurements inside the ROI for a given month are considered. Fig. 4 shows the ensemble of SIF data, where the thick line is the median of all six time series. As we have two different polarizations $(\mathrm{P}, \mathrm{S})$ and three different calibration procedures (seasonal, annual, spline-based), there are a total of six SIF time series which constitutes the aforementioned ensemble. The bottom panel shows the anomalies, and the shaded area visualizes the respective minimum and maximum value of the given month to show the spread of the ROI-averaged SIF. We find that the variability in the six SIF time series is mostly from the two different polarizations, rather than the calibration methodologies. Months with less than 100 measurements are dropped from both the visualization and the analysis, which affects only December 2012 and January 2015 when GOSAT was only partially operative due to instrumental issues.

The anomalies in Fig. 4 (bottom) are calculated as the difference between the current month and the median of all of the same months over the seven-year period. While the time series itself does not immediately reveal any striking features, the anomalies show several important ones. Given this relatively short period of seven years, only one month shows an anomalous value beyond $3 \sigma$ (five months beyond $2 \sigma$ ). We conclude that this short time period does not have a clear baseline, and using a simple threshold based on the standard deviation, will result in either too few or too many anomalies. We point to two studies by Sun et al. (2015) and Wolf et al. (2016), which both analyze drought events with respect to a similarly short baseline. Wolf et al. (2016) establish flux anomalies from three eddy covariance towers based on a 200810 baseline, Sun et al. (2015) investigate the 2011 drought over Texas and the 2012 drought over most parts of the central US respectively, through SIF retrieved from GOME- 2 in the 2007-13 time period. While the 2011 and 2012 anomalies are both apparent in the given time period, we argue that their magnitude might be wrongly assessed if not compared against the other anomalies. It is therefore important to look at every year and potential anomaly within the context of other climatological and agricultural drivers. In chronological order, the major anomalies can be easily identified and related to known meteorological events.
Starting in 2010, we see the effects of the rapid El Niño-La Niña transition, which brought anomalous rain to the Corn Belt in the summer months and drove plant growth (USDA, 2011). This is confirmed through the TRMM/TPMA rainfall anomaly that can be seen in Fig. 5, second row.

In 2011, we see a small negative anomaly for spring, despite average precipitation and temperatures for that season. The reason for the negative anomaly is hinted at by the positive GRACE anomaly for 2011 (Fig. 5 top row). Large amounts of melting snow in the northern Corn Belt, as well as high precipitation in the south eastern corner (Missouri) have caused massive flooding of the Mississippi and Missouri rivers. As most parts of the ROI have not seen any increased rainfall, the precipitation anomaly plot in Fig. 5 (second row) does not show any significant outlier. The flooded areas, however, are visible as a positive anomaly in the GRACE data. While many farmers in the Mississippi River Valley were affected by planting delays due to levee breaches (Olson and Morton, 2012), productive states like Iowa, Nebraska and Kansas were not as severely impacted, hence the lack of a pronounced anomaly (USDA, 2012).

The two anomalies in 2012 are the most well-known and moststudied ones (e.g. Wolf et al. (2016)). In short, a warm winter and warm spring (see LST anomalies in Fig. 5 third row) caused early and fast vegetation growth. In the following summer, however, anomalously low precipitation (Fig. 5, second row) was responsible for drought conditions. As a consequence of the early spring onset due to warm temperatures, the plants used up soil water reserves quicker and depleted the soil of moisture, thus exacerbating the drought even further. This 2012 drought was one of the most severe droughts in recorded history, with conditions comparable to the 1930's dustbowl era. The drought conditions are also evident in the soil moisture (Fig. 5 last row) anomalies, as well as the GRACE water storage anomalies (Fig. 5 top row).

In 2013 and 2014, we again see a negative anomaly for spring and early summer. For these two years, the anomalies have similar causes. In the spring months, high precipitation and cool temperatures delayed the planting process - corn seed planting is generally done on warm and dry days (Choi et al., 2017; Kucharik, 2008) - and also caused slow maturing of crops. The delayed planting is evident in the USDA-NASS surveys, which shows that the planting progress by calendar week 18 was lowest in the years 2013 and 2014 (USDA, 2014; 2015).

The following two years exhibit positive SIF anomalies. In 2015, near-ideal temperatures and favorable rainfall have led to good growing and maturing conditions for corn and soybeans, despite the rainfall distribution being sub-optimal - the southern and eastern regions of the Corn Belt experienced more excessive rain. 2016 proved to be an even better year for crop production than 2015, and this is reflected in the SIF anomaly. After an intense El Niño in 2015, the quick transition to a weak La Niña, and a wet summer has provided ideal conditions for crops (USDA, 2016; 2017).

A short summary is given in Table 2. The USDA-NASS crop summary reports highlight the fact that almost every year between 2010 and 2016 had one or more meteorological events occur which impacted the Corn Belt agriculture.

\subsection{Flux inversion}

SIF is intrinsically linked to primary production (GPP) as it is a byproduct of the photosynthetic process that ultimately leads to carbon fixation. As such, the relationship between SIF and GPP has been explored early on when global-scale retrievals of SIF were performed (Frankenberg et al., 2011; Guanter et al., 2012; Joiner et al., 2011). The SIF-GPP relationship has previously been described as linear when aggregrated on a regional spatial scale and with time, with a potential dependence on biome. Recent studies, however, have shown that the SIF-GPP relationship can change significantly when plants undergo stress, such as during a drought (Wieneke et al., 2018; Wohlfahrt et al., 
Table 2

Summary of the SIF anomalies, their signs and corresponding events highlighted in the annual USDA-NASS crop summary reports.

\begin{tabular}{|c|c|c|}
\hline Year & Sign & Details \\
\hline 2010 & + & $\begin{array}{l}\text { Quick El Niño-La Niña transition, } \\
\text { high precipitation during summer }\end{array}$ \\
\hline 2011 & - & $\begin{array}{l}\text { Snow melt caused flooding, delaying } \\
\text { planting in } \mathrm{MN}, \mathrm{SD}, \mathrm{ND} \text {, and } \mathrm{WI}\end{array}$ \\
\hline 2012 & $+1-$ & $\begin{array}{l}\text { Warm spring induced early onset, } \\
\text { summer drought collapsed yield }\end{array}$ \\
\hline 2013 & - & Cold and wet spring delayed planting \\
\hline 2014 & - & -same- \\
\hline 2015 & + & $\begin{array}{l}\text { Good planting and growing conditions, } \\
\text { despite large rainfall due to El Niño }\end{array}$ \\
\hline 2016 & + & $\begin{array}{l}\text { Weak La Niña/wet summer for } \\
\text { good conditions }\end{array}$ \\
\hline
\end{tabular}

2018).

We compare gross (GPP) and net flux (NEE) anomalies from the Carnegie-Ames-Stanford-Approach (CASA) model (Potter et al., 1993), as well as net flux anomalies obtained through a global inversion of GOSAT $\mathrm{XCO}_{2}$ total column measurements (see Section 2.2) to the SIF anomalies. Fig. 7 shows that the large drought event of 2012 is represented in both gross and net fluxes - several other anomalies (2010, 2011, 2015) are also well-represented in both model fluxes, and the fluxes obtained through inversions. The surface fluxes anomalies here are also sampled at the GOSAT measurement locations.

While we did not perform high-resolution flux inversions as done by Lauvaux et al. (2012), we do see that the a posteriori net $\mathrm{CO}_{2}$ fluxes, integrated over the growing period April-July, agree better with the cumulative SIF when compared to CASA net fluxes, as shown in Fig. 8. The CASA GPP, however, compares even better ( $r=0.92$, not shown). Again, this is most likely due to CASA GPP being constrained by NDVI, and a similar analysis between cumulative SIF and cumulative NDVI yielding good agreement already ( $r=0.76$, not shown).

SIF is generally thought to be a proxy for gross carbon uptake, rather than net flux, so the good agreement between integrated fluxes and SIF might seem surprising. The difference between total carbon uptake and net fluxes are usually summarized in the respiration term which (over land surfaces) comprises plant respiration, soil respiration and litter decomposition. From a flux inversion point of view, respiration and its components cannot be easily disentangled from the net fluxes. Byrne et al. (2018) have published efforts using models and SIF to decompose a posteriori (net) fluxes from respiration. Given that respiration roughly follows the trend of total uptake, and that we observe a large spatially-averaged and time-integrated composite signal, the agreement between a posteriori fluxes from the inversion and GOSAT SIF is reasonable.

\subsection{Crop planting and yield}

The US Corn Belt is an exceptional region. As recently investigated by Alter et al. (2017), it even generates its own climate, with the agricultural intensification resulting in cooler temperatures and increased rainfall. Despite the ROI being almost $1800 \times 10^{9} \mathrm{~m}^{2}$ in area, around half of it is irrigated cropland. Meteorological conditions are thus not the only factor in determining the vegetation onset and productivity of one given season. It was pointed out in Section 3.1 that for certain years, the springtime rainfall has caused delays in the planting of crops. To show that SIF indeed captures the delays in planting, we investigate USDA-NASS survey data and compare relevant annual aggregates from the surveys with quantities derived from the SIF time series. In these reports, the percentage of area planted is recorded based on farmer surveys. We translate these weekly state-wide data for the whole ROI by multiplying with the total planted area for that given year and state in order to obtain an effective "planted area". We compare this number for every year against the integrated (or cumulative) SIF radiances (monthly ROI averages) from April onwards to June. To capture the uncertainty in the aggregated SIF, we use regional sub-sets. For each month, the polarization-averaged single SIF retrievals are grouped into regional clusters through the $k$-means algorithm, with each cluster having about 50 values. The standard error of each cluster $i$ $\left(\sigma_{\bar{C}, i}=\sigma_{C, i} / \sqrt{N_{C, i}}\right.$, with $N_{C, i}$ being the total number of measurements in cluster $i$ ) is then calculated, along with the mean of all $\sigma_{\bar{C}, i}$ for the given month. This mean standard error is then considered the uncertainty of the ROI-averaged SIF for that month, and several of these values are then added in quadrature to obtain the variance on the cumulative SIF over several months, which are displayed as uncertainty bars in Fig. 9 (and all other figures containing cumulative SIF).

The result for both corn and soybeans is shown in Fig. 9. It shows that the time-integrated SIF radiances correspond well to the crop planting progress of that given year at the first week of May (week 18). Week 18 was chosen as a reference point as it is generally in the first half of the planting season, which usually starts in early April, or week 14. Grassini et al. (2011) state the mean planting date (or sowing date) at day 117 of the year (last week of April) for the years 2005 to 2007 for their study in Nebraska. Between 2010 and 2016, planting progress has reached close to $100 \%$ by week 23 (beginning of June) according to USDA-NASS surveys, and no planting has been done after week 26 . Before week 17, the variability of planting is too high between nine states and the ROI-averaged SIF is therefore not representative of the Corn Belt as a whole. Table 3 shows the correlation coefficients of the relationships between SIF and planting progress (as in Fig. 9) along with the coefficient of variation $(\mathrm{COV}, \sigma / \mu)$ of the planting progress of the given week for all states, averaged over the 7 years. A higher value indicates larger variation in planting progress between the nine states.

The SIF radiances do not only reflect the crop status during the growing season. Also the total corn and soybean yield for the entire year has an apparent linear relationship with the cumulative SIF radiances from July until October (harvest), as can be seen in Fig. 10. The record-low yield due to the 2012 drought is also highly apparent in the figure. As the SIF integration time goes past the reference planting date, we assume that the cumulative SIF tracks the planting onset by proxy through the development of the crops in their first three months.

This type of analysis has been published before, recently in a study by Glennie and Anyamba (2018), in which they use a long-term (1982-2014) NDVI record from the Advanced Very High Resolution Radiometer (AVHRR) instrument and compare them to yield data. Due to the high spatial resolution of the AVHRR instrument $(8 \mathrm{~km})$ and coverage ( $2500 \mathrm{~km}$ swath width), their cumulative NDVI-to-yield relationship could be established year-to-year, comparing annual yields for individual counties in the Corn Belt. They find moderately strong correlations $(r>0.58)$ which varies for every year. As Glennie and Anyamba (2018) have done, we have also detrended the crop yields using a linear fit through the mean yields from 1955 onwards, although the impact on the results is small, mostly due to the short time period of seven years.

The observed good relationship between cumulative SIF, and crop planting and crop yield is consistent with the relatiionship between SIF and NDVI/EVI time series anomalies $(r>0.4$, see Fig. 6). The

\section{Table 3}

Relationship between cumulative SIF (Apr-Jun) and planting progress for different weeks of the year, each row representing the same analysis as in Fig. 9. Soybean planting generally does not start until week 17 .

\begin{tabular}{lllll}
\hline Week Nr. & COV Corn & COV Soy & Corn & Soy \\
\hline 16 & 1.04 & 1.37 & $r=0.89$ & $r=0.52$ \\
17 & 0.80 & 1.06 & $r=0.92$ & $r=0.85$ \\
18 & 0.48 & 0.97 & $r=0.95$ & $r=0.94$ \\
19 & 0.31 & 0.62 & $r=0.83$ & $r=0.89$ \\
20 & 0.18 & 0.45 & $r=0.84$ & $r=0.83$ \\
\hline
\end{tabular}



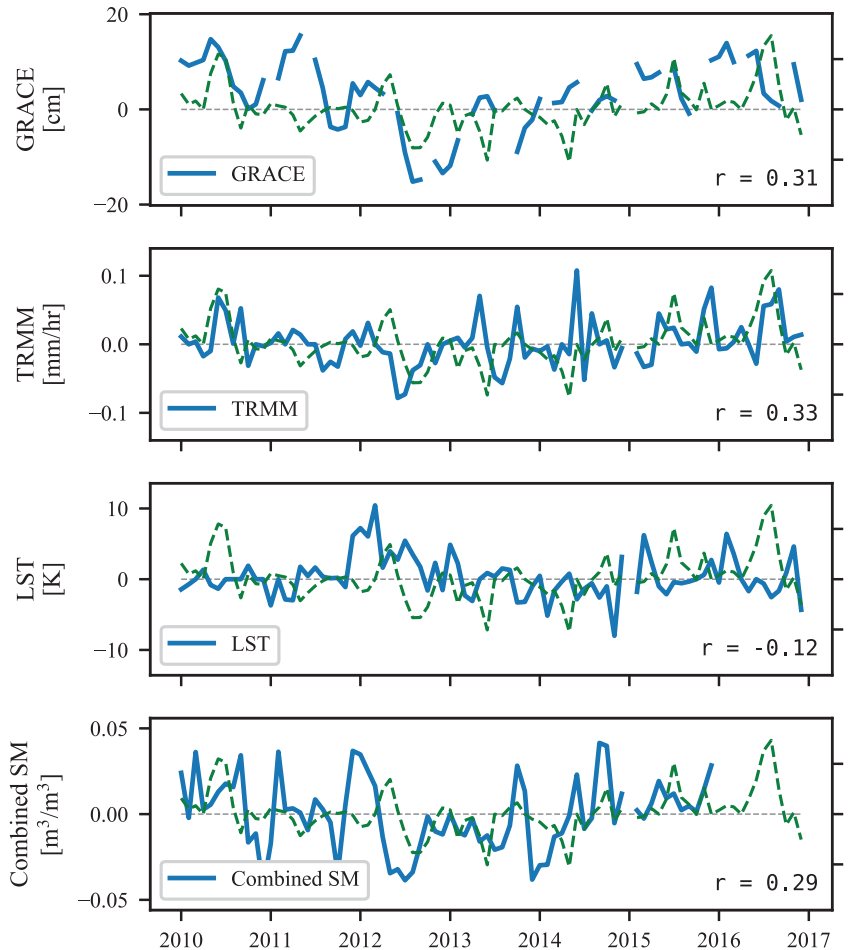

Fig. 5. Anomalies of GRACE water equivalent thickness (cm), precipitation, land surface temperature and soil moisture (all in blue), along with SIF anomalies (dashed, green). The ordinate axes ticks on the left hand side refer to the non-SIF anomalies (GRACE, precipitation, LST, soil moisture). SIF anomalies are plotted for visual comparison, and tick labels have been omitted for better legibility. The GRACE time series has several gaps, which is mainly due to aging batteries on the GRACE satellite. (For interpretation of the references to colour in this figure legend, the reader is referred to the web version of this article.)

predictive power of hyperspectral indices from remote sensing instruments in characterizing and predicting crop yield has been demonstrated in the past, such as by Shanahan et al. (2001), Prasad et al. (2006), Becker-Reshef et al. (2010), Mkhabela et al. (2011), Sakamoto et al. (2014) and many more. For the case of the Corn Belt, (monthly cumulative) NDVI/EVI are slightly worse predictors than SIF for planting ( $r=0.91 / r=0.88$ for corn) but similarly good predictors when looking at yield $(r=0.95 / r=0.94$ for corn), see Fig. 11. Leaf area index (LAI) and fractional vegetation cover (FVC) correlate equally well with $r=0.95$ and $r=0.92$ for corn yield and corn planting progress $(r=0.93 / r=0.93)$.

A potential weakness regarding the relationship between SIF and crop yields is the following. We cannot simply deduce from the SIF measurements alone, whether GOSAT is observing stronger SIF due to the photosynthetic response of crops, or if the footprints are merely seeing larger amounts of vegetated area. We can easily establish that the retrieved surface reflectivity (Lambertian albedo) is not contributing to the observed relationships, as the SIF and albedo anomalies are not correlated $(r<0.11)$. To further exclude the possibility of GOSAT SIF measuring only the change in vegetated area, we construct three control time series to compare against the results seen in Fig. 10.

The first control aims at the relationship between total planted area in the nine states against crop yield, where the planted area and yield values are separate for corn and soybeans. This is shown in Fig. 12. We see a positive correlation for soybeans $(r=0.71)$, whereas for corn, there is a surprising negative correlation $(r=-0.63)$ with low statistical significance $(p=.13)$. This negative correlation for corn is solely due to the year 2012, removing that one data point reduces the correlation coefficient to $r=0.00$, which is already hinted by the large p-value of
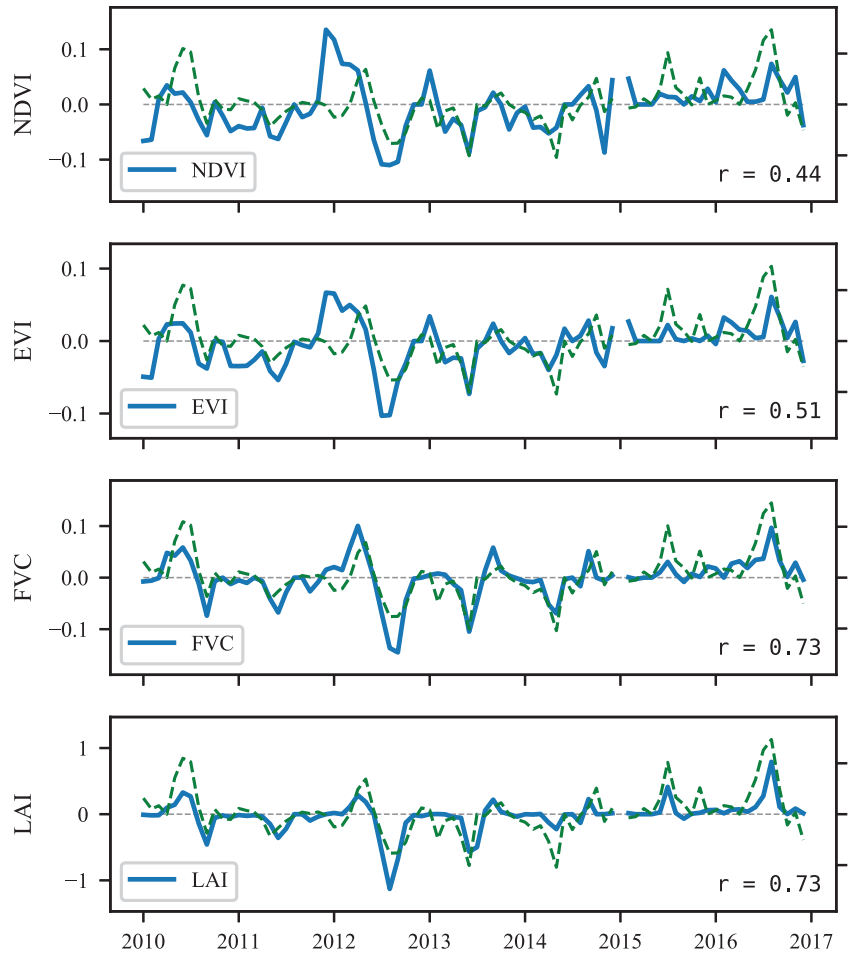

Fig. 6. SIF anomaly (green dashed, tick labels on right were omitted) compared to the normalized differential vegetation index (NDVI), enhanced vegetation index (EVI), fractional vegetation cover (FVC) and leaf area index anomalies (LAI). Both FVC and LAI reproduce almost the same anomalies as SIF with the main difference being the strength of the positive 2010 anomaly, and LAI not showing any anomaly in 2014 at all. NDVI and EVI show a more extended positive anomaly for the $2011 / 2012$ winter season, mainly due to the low amount of snow cover in that winter as a result of above-average temperatures. This is supported by the soil moisture anomaly (Fig. 5). (For interpretation of the references to colour in this figure legend, the reader is referred to the web version of this article.)
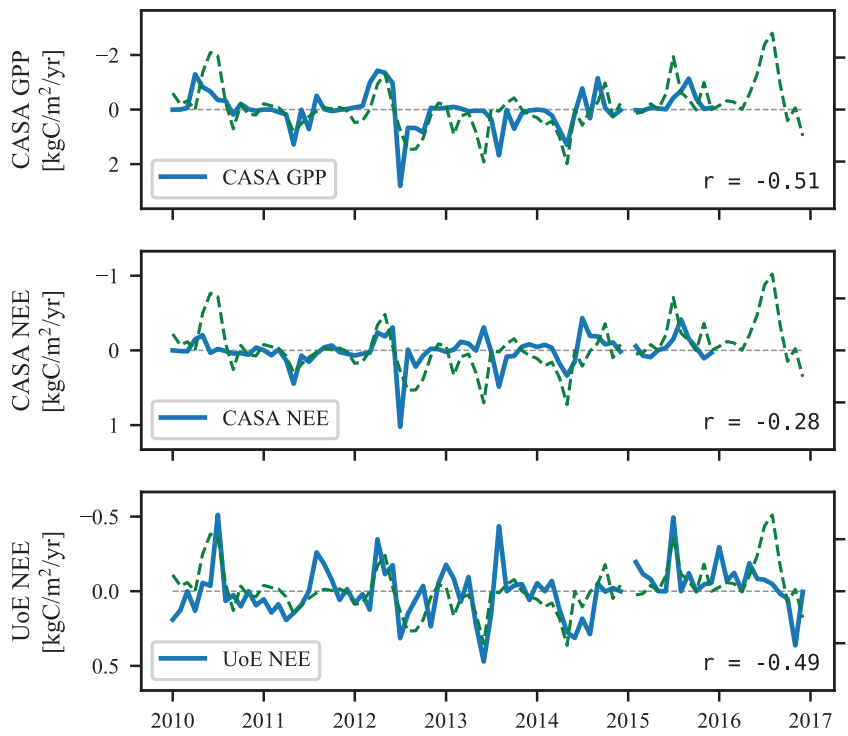

Fig. 7. Flux anomalies $\left[\mathrm{gC} / \mathrm{m}^{2} / \mathrm{yr}\right]$ overlaid on top of SIF anomalies $\left[\mathrm{mW} / \mathrm{m}^{2} /\right.$ $\mathrm{sr} / \mathrm{nm}$ ]. We use CASA NEE (close to NPP) as a priori net surface fluxes.

0.13. The positive and significant correlation for soybeans is explained through both the steadily increasing yields together with a general increase in soybean planting. The USDA projects soybeans to reach similar levels to corn in terms of amount of planted area in the near 


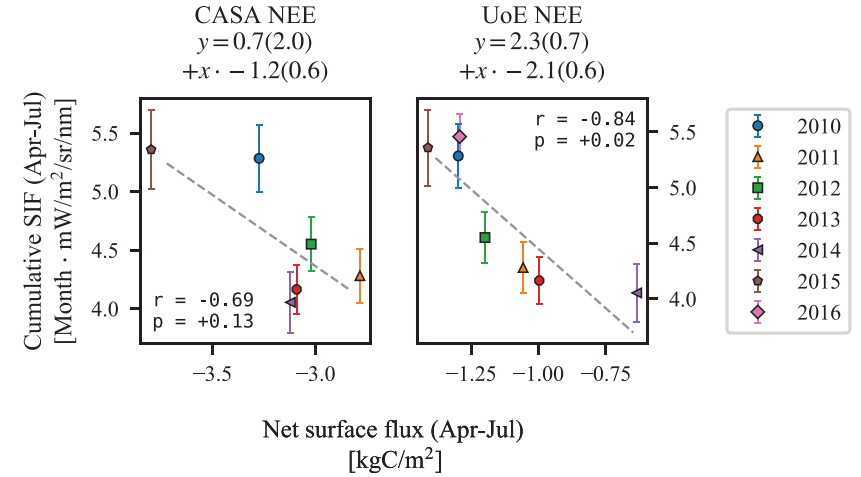

Fig. 8. Cumulative SIF from April to July as a function of net surface carbon fluxes, integrated in the same period, from CASA and the GOSAT-based flux inversion. Note that while the University of Edinburgh (UoE) inversion scheme uses CASA output as prior information, the a posteriori fluxes provide better agreement with the cumulative SIF. This makes a good case that the GOSAT $\mathrm{XCO}_{2}$ data indeed provide a direct constraint on the surface fluxes.

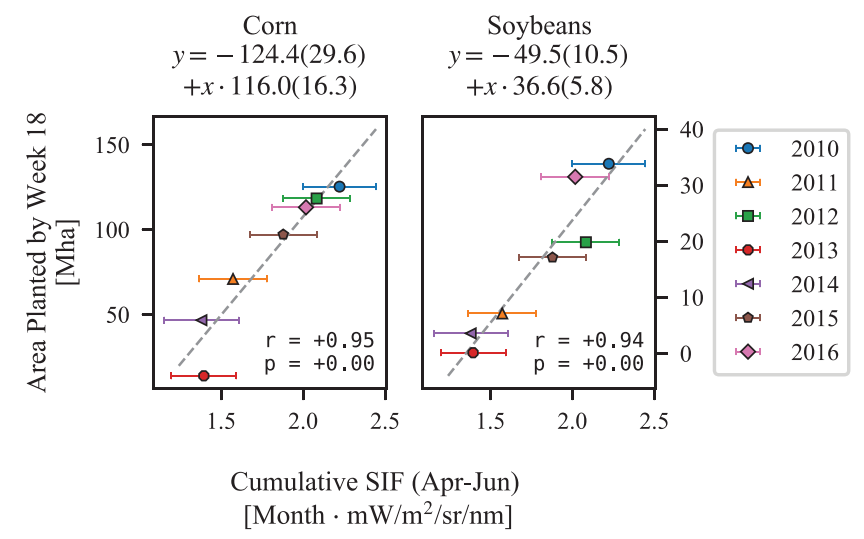

Fig. 9. Crop planting progress at week 18 as a function of time-integrated monthly SIF radiances from February to June. Low values for the years 2013 and 2014 are the result of planting delays due to rainfall and cold temperatures (see Section 3.1). The values in the brackets within the regression equation (above plots) is the uncertainty of the fitted slope and offset.

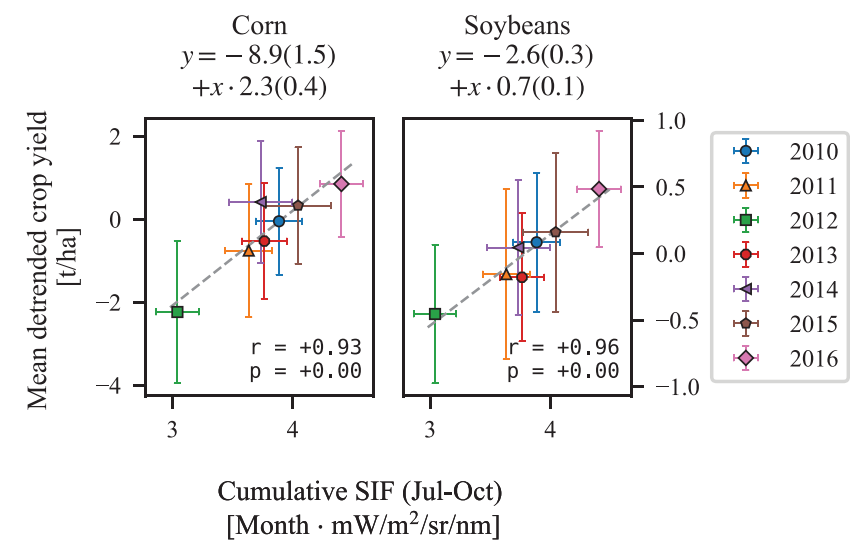

Fig. 10. Annual crop yield from June to October as a function of the timeintegrated monthly SIF radiances from July to October. The uncertainty bars for crop yield represent the standard deviation for the values of all nine states within the ROI.

future (USDA, 2019b). With the used auxiliary data, we cannot distinguish whether a specific GOSAT footprint covered a soy field or a corn field (or any other crop) at the time of measurement. Hence we cannot completely reject the possibility that the SIF signal we see in Fig. 10 is due to mainly covering soybean fields. Since most farmers in the Corn
Belt practice individual crop rotation between corn and soybeans (Suyker and Verma, 2012), it is most likely that we are sampling a mix between corn, soybeans, and to a lesser extent, wheat, and that the relative contribution of each crop does not vary by large amounts over the years. We therefore assume that the SIF-yield relationship is not driven due to sampling that is heavily weighted towards soybean fields.

The second control relies on a similar idea, however focuses on satellite-derived vegetation data. We aggregate the NDVI grid boxes $\left(0.05^{\circ}\right.$ resolution) in the ROI, which according to the ESA CCI LC map have at least $5 \%$ of rainfed cropland land cover classes. For every year between 2010 and 2016, a NDVI map is then created in which every grid cell contains the maximal NDVI value for that year. Finally, the fraction of grid cells which exhibit an NDVI value above 0.3 is calculated. A value of 0.3 is a low enough threshold that should discriminate between a vegetated and non-vegetated surface. This provides a first order estimate of the number of grid cells that contain some level of vegetation. As seen in Fig. 13, this fraction of vegetated area (reduced to crop-covered pixels within the ROI) does not provide a better correlation with crop yields as SIF or vegetation indices themselves. What this analysis shows, however, is that practically every grid cell ( $>98 \%$ ) covering crop fields has been vegetated at some point during the year. Both correlation coefficients are statistically not significant with $p>0.1$, mainly due to the fact that the NDVI fraction only changes by about $1 \%$. As opposed to Fig. 12, we cannot distinguish whether a pixel belongs to a corn or soybean field, and hence cannot split the NDVI fraction into corn and soy components.

For the third control, we investigate a potential sampling bias. Already shown in Fig. 3, there is a variability in terms of the surfaces sampled by GOSAT, mostly a result of changing cloud cover and sampling strategy. We compare the crop yield to the fraction of cropland (as determined by the ESA CCI LC map) that all GOSAT soundings see in a given year. Here we use the same set of soundings that was pre-filtered beforehand, so only individual soundings are considered that cover more than $50 \%$ of the crop type land cover type. The observed correlations at $r<0.61$ are weaker than in Fig. $13(r>0.64)$, but neither relationship seems statistically significant $(p>0.15)$.

Despite the fact that two of the three controls (Fig. 13 and 14) exhibit a moderate correlation with crop yields, the SIF radiances show a much higher one. We thus conclude that GOSAT SIF as well as vegetation indices, do not merely track whether a surface was vegetated, but can also provide information on the vegetation density and yield through the intensity of the signal.

\section{Conclusions}

We have presented a study of the US Corn Belt over the period of 7 years (2010-16) that focuses on inter-annual variability and puts apparent anomalies into the context of agriculture. Several satellite-based data products were used to construct a coherent picture of the vegetation responses, which were mainly interpreted through GOSAT-based SIF with the help of USDA-NASS crop summary reports, which proved an invaluable resource. While we remain careful about claiming SIF to be superior compared to the more traditional reflectance-based vegetation indices, our work hints towards that being the case for this particular region. We were able to make a thorough comparison only because sampling was taken into account very carefully, ensuring that time series anomalies were calculated by considering the spatial extent of GOSAT footprints. By exactly collocating other satellite-based datasets, we are able to keep sampling bias to a minimum when comparing GOSAT SIF to other surface-type and atmospheric variables. While data sparsity is an issue, we are hopeful that in the near future, space-based SIF measurements can play a supporting role in crop monitoring and yield prediction, along with the traditional reflectance-based vegetation indices.

The biggest challenge of this type of analysis remains the particular sampling pattern of GOSAT, which is non-uniform as well as low in the 


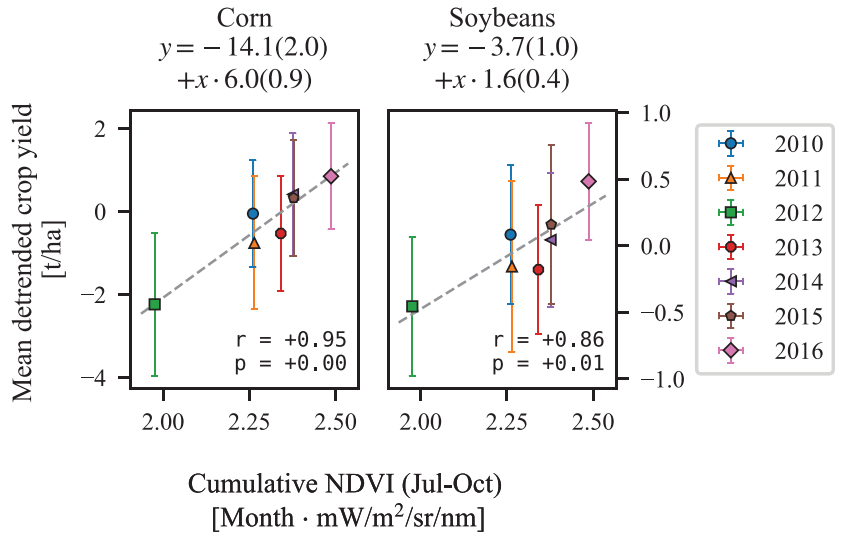

Fig. 11. The relationship between cumulative NDVI and crop yields, similar to the SIF-yield relationship shown in Fig. 10. Both qualitatively and quantitatively, both NDVI and SIF are almost equally good predictors for crop yields, with SIF performing better for soybeans. Note the dynamic range of SIF is higher $(\approx 33 \%)$ than the range of NDVI $(\approx 20 \%)$.
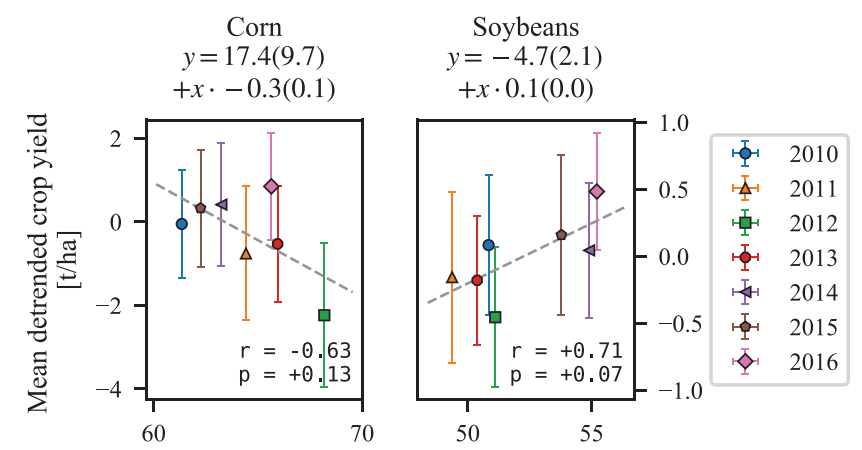

Total Planted Area $\left[10^{6}\right.$ acres $]$

Fig. 12. Crop yield versus the total planted area in that year, with planted area vales for the specific crop.

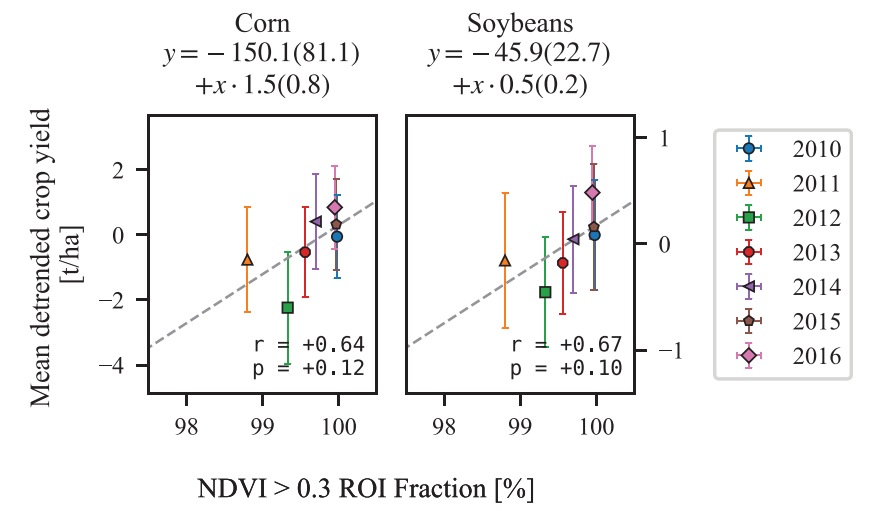

Fig. 13. Detrended crop yield versus the fraction of valid NDVI pixels $>0.3$. The correlation coefficients $r>0.64$ suggest that the annual crop yield is moderately related to the total area of farmed fields for both corn and soybean crops.

total number of measurements in a given time period. Due to the low number of measurements, it is both very difficult to analyze regions much smaller than the Corn Belt, as well as using smaller time intervals than a month. Newer space-based instruments, such as OCO-2 and TROPOMI, however, are capable of measuring SIF at a much higher spatial resolution (Köhler et al., 2018; Sun et al., 2018). Especially TROPOMI has the advantage of being a wide-swath instrument, which provides near-global coverage on a daily basis. Given similar limitations

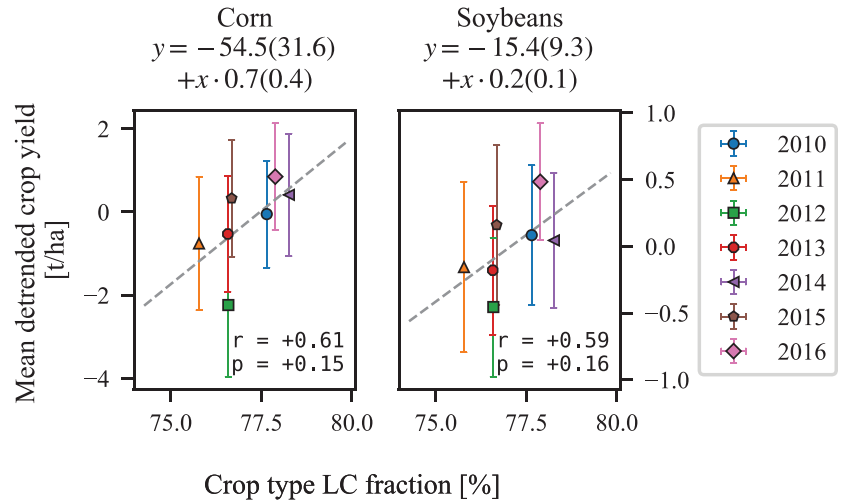

Fig. 14. Relationship between detrended crop yield and the total fraction of LC crop type surface seen in a given year.

on single-retrieval uncertainty, weekly global SIF coverage is feasible. The ESA Earth Explorer Mission FLEX (Drusch et al., 2017) is dedicated to SIF and will launch in 2023. Despite being designed for smaller swath $(150 \mathrm{~km})$, its $300 \mathrm{~m}$ resolution FLORIS instrument will provide an opportunity to observe SIF on the scale of crop fields. Finally, the geostationary GeoCarb instrument (Moore et al., 2018) will provide the opportunity to obtain SIF for the Americas with dense spatial coverage and daily repeats, with the possibility for measuring small areas more than once per day.

\section{Declaration Competing Interest}

The authors declare that they have no known competing financial interests or personal relationships that could have appeared to influence the work reported in this paper.

\section{Acknowledgements}

PS was funded by the ESA Greenhouse Gas Climate Change Initiative (GHG-CCI) as part of a PhD studentship. $\mathrm{HB}, \mathrm{RP}, \mathrm{PP}, \mathrm{LF}$ and TQ were funded via the UK National Centre for Earth Observation at University of Leicester, University of Edinburgh and University of Reading (NCEO grant number: nceo020005).

The GOSAT SIF data was generated via funding from the Copernicus Atmospheric Monitoring Service (CAMS_41) and the GOSAT $\mathrm{XCO}_{2}$ was produced as part of ESA GHG-CCI and Copernicus Climate Change Service (C3S_312a Lot 6 and C3S_312b Lot 2).

We thank the Japanese Aerospace Exploration Agency, National Institute for Environmental Studies, and the Ministry of Environment for the GOSAT data and their continuous support as part of the Joint Research Agreement.

This research used the ALICE High Performance Computing Facility at the University of Leicester, as well as the JASMIN (CEMS) infrastructure at the Rutherford Appleton Laboratory for the GOSAT retrievals and analysis.

\section{References}

Alter, R.E., Douglas, H.C., Winter, J.M., Eltahir, E.A.B., 2017. Twentieth century regional climate change during the summer in the central United States attributed to agricultural intensification. Geophys. Res. Lett. 45 (3), 1586-1594. https://doi.org/10. 1002/2017GL075604.

Arora, G., Wolter, P.T., 2018. Tracking land cover change along the western edge of the US Corn Belt from 1984 through 2016 using satellite sensor data: observed trends and contributing factors. J. Land Use Sci. 13 (1-2), 59-80. https://doi.org/10.1080/ 1747423X.2018.1466001.

Becker-Reshef, I., Vermote, E., Lindeman, M., Justice, C., 2010. A generalized regressionbased model for forecasting winter wheat yields in Kansas and Ukraine using MODIS data. Remote Sens. Environ. 114 (6), 1312-1323. https://doi.org/10.1016/j.rse. 2010.01.010.

Bontemps, S., Defourny, P., Radoux, J., Van Bogaert, E., Lamarche, C., Achard, F., 
Mayaux, P., Boettcher, M., Brockmann, C., Kirches, G., et al., 2013. Consistent global land cover maps for climate modelling communities: current achievements of the ESAs land cover CCI. Proceedings of the ESA Living Planet Symposium. pp. 9-13.

Buchwitz, M., Reuter, M., Schneising, O., Bovensmann, H., Burrows, J.P., Boesch, H., Anand, J., Parker, R., Detmers, R.G., Aben, I., Hasekamp, O.P., Crevoisier, C., Armante, R., Zehner, C., Schepers, D., 2018. Copernicus climate change service (c3s) global satellite observations of atmospheric carbon dioxide and methane. Adv. Astron. Sci. Technol. 1 (1), 57-60. https://doi.org/10.1007/s42423-018-0004-6.

Buchwitz, M., Reuter, M., Schneising, O., Hewson, W., Detmers, R.G., Boesch, H., Hasekamp, O.P., Aben, I., Bovensmann, H., Burrows, J.P., Butz, A., Chevallier, F., Dils, B., Frankenberg, C., Heymann, J., Lichtenberg, G., De Mazire, M., Notholt, J., Parker, R., Warneke, T., Zehner, C., Griffith, D.W.T., Deutscher, N.M., Kuze, A., Suto, H., Wunch, D., 2017. Global satellite observations of column-averaged carbon dioxide and methane: the GHG-CCI XCO $\mathrm{XCO}_{2}$ and $\mathrm{XCH}_{4} \mathrm{CRDP} 3$ data set. Remote Sens. Environ. 203, 276-295. https://doi.org/10.1016/j.rse.2016.12.027. Earth Observation of Essential Climate Variables

Byrne, B., Wunch, D., Jones, D., Strong, K., Deng, F., Baker, I., Köhler, P., Frankenberg, C., Joiner, J., Arora, V.K., et al., 2018. Evaluating GPP and respiration estimates over northern midlatitude ecosystems using solar-induced fluorescence and atmospheric $\mathrm{CO}_{2}$ measurements. J. Geophys. Res. 123 (9), 2976-2997. https://doi.org/10.1029/ 2018JG004472.

Chevallier, F., Maksyutov, S., Bousquet, P., Bréon, F.-M., Saito, R., Yoshida, Y., Yokota, T., 2009. On the accuracy of the $\mathrm{CO}_{2}$ surface fluxes to be estimated from the GOSAT observations. Geophys. Res. Lett. 36 (19). https://doi.org/10.1029/2009GL040108.

Choi, Y.-S., Gim, H.-J., Ho, C.-H., Jeong, S.-J., Park, S.K., Hayes, M.J., 2017. Climatic influence on corn sowing date in the Midwestern United States. Int. J. Climatol. 37 (3), 1595-1602. https://doi.org/10.1002/joc.4799.

Cogan, A.J., Boesch, H., Parker, R.J., Feng, L., Palmer, P.I., Blavier, J.-F.L., Deutscher, N.M., Macatangay, R., Notholt, J., Roehl, C., Warneke, T., Wunch, D., 2012. Atmospheric carbon dioxide retrieved from the Greenhouse gases Observing SATellite (GOSAT): comparison with ground-based TCCON observations and GEOS Chem model calculations. J. Geophys. Res. 117 (D21). https://doi.org/10.1029/ 2012JD018087.

Didan, K., 2015. MYD13C1 MODIS/Aqua Vegetation Indices 16-Day L3 Global 0.05Deg CMG V006. https://doi.org/10.5067/MODIS/MYD13C1.006. Distributed by NASA EOSDIS LP DAAC

Dorigo, W., Wagner, W., Albergel, C., Albrecht, F., Balsamo, G., Brocca, L., Chung, D., Ertl, M., Forkel, M., Gruber, A., Haas, E., Hamer, P.D., Hirschi, M., Ikonen, J., de Jeu, R., Kidd, R., Lahoz, W., Liu, Y.Y., Miralles, D., Mistelbauer, T., Nicolai-Shaw, N., Parinussa, R., Pratola, C., Reimer, C., van der Schalie, R., Seneviratne, S.I., Smolander, T., Lecomte, P., 2017. ESA CCI soil moisture for improved Earth system understanding: state-of-the art and future directions. Remote Sens. Environ. 203, 185-215. https://doi.org/10.1016/j.rse.2017.07.001. Earth Observation of Essential Climate Variables

Drusch, M., Moreno, J., Del Bello, U., Franco, R., Goulas, Y., Huth, A., Kraft, S., Middleton, E.M., Miglietta, F., Mohammed, G., et al., 2017. The fluorescence explorer mission concept ESAs Earth Explorer 8. IEEE Trans. Geosci. Remote Sens. 55 (3), 1273-1284. https://doi.org/10.1109/TGRS.2016.2621820.

Feng, L., Palmer, P.I., Boesch, H., Dance, S., 2009. Estimating surface $\mathrm{CO}_{2}$ fluxes from space-borne $\mathrm{CO}_{2}$ dry air mole fraction observations using an ensemble kalman filter. Atmos. Chem. Phys. 9 (8), 2619-2633. https://doi.org/10.5194/acp-9-2619-2009.

Feng, L., Palmer, P.I., Parker, R.J., Deutscher, N.M., Feist, D.G., Kivi, R., Morino, I., Sussmann, R., 2016. Estimates of European uptake of $\mathrm{CO}_{2}$ inferred from GOSAT $\mathrm{XCO}_{2}$ retrievals: sensitivity to measurement bias inside and outside Europe. Atmos. Chem. Phys. 16 (3), 1289-1302. https://doi.org/10.5194/acp-16-1289-2016.

Frankenberg, C., Fisher, J.B., Worden, J., Badgley, G., Saatchi, S.S., Lee, J.-E., Toon, G.C., Butz, A., Jung, M., Kuze, A., Yokota, T., 2011. New global observations of the terrestrial carbon cycle from GOSAT: patterns of plant fluorescence with gross primary productivity. Geophys. Res. Lett. 38 (17). https://doi.org/10.1029/2011GL048738.

Frankenberg, C., ODell, C., Guanter, L., McDuffie, J., 2012. Remote sensing of near-infrared chlorophyll fluorescence from space in scattering atmospheres: implications for its retrieval and interferences with atmospheric $\mathrm{CO}_{2}$ retrievals. Atmos. Meas. Tech. 5 (8), 2081-2094. https://doi.org/10.5194/amt-5-2081-2012.

Glennie, E., Anyamba, A., 2018. Midwest agriculture and ENSO: a comparison of AVHRR NDVI3g data and crop yields in the United States Corn Belt from 1982 to 2014. Int. J. Appl. Earth Observ. Geoinf. 68, 180-188. https://doi.org/10.1016/j.jag.2017.12. 011.

Grassini, P., Specht, J.E., Tollenaar, M., Ciampitti, I., Cassman, K.G., 2015. Chapter 2 High-yield maizesoybean cropping systems in the US Corn Belt. In: Sadras, V.O., Calderini, D.F. (Eds.), Crop Physiology, second ed. Academic Press, San Diego, pp 17-41. https://doi.org/10.1016/B978-0-12-417104-6.00002-9.

Grassini, P., Thorburn, J., Burr, C., Cassman, K.G., 2011. High-yield irrigated maize in the Western US Corn Belt: I. On-farm yield, yield potential, and impact of agronomic practices. Field Crops Res. 120 (1), 142-150. https://doi.org/10.1016/j.fcr.2010.09. 012.

Green, T.R., Kipka, H., David, O., McMaster, G.S., 2018. Where is the USA corn belt, and how is it changing? Sci. Total Environ. 618, 1613-1618. https://doi.org/10.1016/j. scitotenv.2017.09.325

Guanter, L., Frankenberg, C., Dudhia, A., Lewis, P.E., Gmez-Dans, J., Kuze, A., Suto, H., Grainger, R.G., 2012. Retrieval and global assessment of terrestrial chlorophyll fluorescence from GOSAT space measurements. Remote Sens. Environ. 121, 236-251. https://doi.org/10.1016/j.rse.2012.02.006.

Guanter, L., Zhang, Y., Jung, M., Joiner, J., Voigt, M., Berry, J.A., Frankenberg, C., Huete, A.R., Zarco-Tejada, P., Lee, J.-E., et al., 2014. Global and time-resolved monitoring of crop photosynthesis with chlorophyll fluorescence. Proc. Natl. Acad. Sci. 111 (14), E1327-E1333. https://doi.org/10.1073/pnas.1320008111.
Huffman, G.J., Bolvin, D.T., Nelkin, E.J., Wolff, D.B., Adler, R.F., Gu, G., Hong, Y., Bowman, K.P., Stocker, E.F., 2007. The TRMM multisatellite precipitation analysis (TMPA): quasi-global, multiyear, combined-sensor precipitation estimates at fine scales. J. hydrometeorol. 8 (1), 38-55. https://doi.org/10.1175/JHM560.1.

Johnson, D.M., 2014. An assessment of pre-and within-season remotely sensed variables for forecasting corn and soybean yields in the United States. Remote Sens. Environ. 141, 116-128. https://doi.org/10.1016/j.rse.2013.10.027.

Joiner, J., Guanter, L., Lindstrot, R., Voigt, M., Vasilkov, A.P., Middleton, E.M., Huemmrich, K.F., Yoshida, Y., Frankenberg, C., 2013. Global monitoring of terrestrial chlorophyll fluorescence from moderate-spectral-resolution near-infrared satellite measurements: methodology, simulations, and application to GOME-2. Atmosph. Meas. Tech. 6 (10), 2803-2823. https://doi.org/10.5194/amt-6-2803-2013.

Joiner, J., Yoshida, Y., Vasilkov, A.P., Middleton, E.M., et al., 2011. First observations of global and seasonal terrestrial chlorophyll fluorescence from space. Biogeosciences 8 (3), 637-651. https://doi.org/10.5194/bg-8-637-2011.

Köhler, P., Frankenberg, C., Magney, T.S., Guanter, L., Joiner, J., Landgraf, J., 2018. Global retrievals of solar-induced chlorophyll fluorescence with TROPOMI: first results and intersensor comparison to OCO-2. Geophys. Res. Lett. 45 (19), 10-456. https://doi.org/10.1029/2018GL079031.

Köhler, P., Guanter, L., Joiner, J., 2015. A linear method for the retrieval of sun-induced chlorophyll fluorescence from GOME-2 and SCIAMACHY data. Atmos. Meas. Tech. 8 (6), 2589-2608. https://doi.org/10.5194/amt-8-2589-2015.

Kucharik, C.J., 2008. Contribution of planting date trends to increased maize yields in the central United States. Agron. J. 100 (2), 328-336. https://doi.org/10.2134/ agronj2007.0145.

Landerer, F.W., Swenson, S.C., 2012. Accuracy of scaled GRACE terrestrial water storage estimates. Water Resour. Res. 48 (4). https://doi.org/10.1029/2011WR011453.

Lauvaux, T., Schuh, A.E., Uliasz, M., Richardson, S., Miles, N., Andrews, A.E., Sweeney, C., Diaz, L.I., Martins, D., Shepson, P.B., et al., 2012. Constraining the $\mathrm{CO}_{2}$ budget of the corn belt: exploring uncertainties from the assumptions in a mesoscale inverse system. Atmos. Chem. Phys. 12 (1). https://doi.org/10.5194/acp-12-337-2012.

Lee, J.-E., Frankenberg, C., van der Tol, C., Berry, J.A., Guanter, L., Boyce, C.K., Fisher, J.B., Morrow, E., Worden, J.R., Asefi, S., et al., 2013. Forest productivity and water stress in Amazonia: Observations from GOSAT chlorophyll fluorescence. Proc. R. Soc. B 280 (1761), 20130171. https://doi.org/10.1098/rspb.2013.0171.

Liu, L., Zhang, X., Yu, Y., Gao, F., Yang, Z., 2018. Real-time monitoring of crop phenology in the Midwestern United States using VIIRS observations. Remote Sens. 10 (10), 1540. https://doi.org/10.3390/rs10101540.

Maisongrande, P., Duchemin, B., Dedieu, G., 2004. VEGETATION/SPOT: an operational mission for the Earth monitoring; presentation of new standard products. Int. J. Remote Sens. 25 (1), 9-14. https://doi.org/10.1080/0143116031000115265.

Meroni, M., Rossini, M., Guanter, L., Alonso, L., Rascher, U., Colombo, R., Moreno, J., 2009. Remote sensing of solar-induced chlorophyll fluorescence: review of methods and applications. Remote Sens. Environ. 113 (10), 2037-2051. https://doi.org/10. 1016/j.rse.2009.05.003.

Mkhabela, M.S., Bullock, P., Raj, S., Wang, S., Yang, Y., 2011. Crop yield forecasting on the canadian prairies using MODIS NDVI data. Agric. Forest Meteorol. 151 (3), 385-393. https://doi.org/10.1016/j.agrformet.2010.11.012.

Moore, B., 2018. The potential of the geostationary carbon cycle observatory (GeoCarb) to provide multi-scale constraints on the carbon cycle in the Americas. Front. Environ. Sci. 6, 109. https://doi.org/10.3389/fenvs.2018.00109.

Oda, T., Maksyutov, S., 2011. A very high-resolution $(1 \mathrm{~km} \times 1 \mathrm{~km})$ global fossil fuel $\mathrm{CO}_{2}$ emission inventory derived using a point source database and satellite observations of nighttime lights. Atmos. Chem. Phys. 11 (2), 543-556. https://doi.org/ 10.5194/acp-11-543-2011.

Olsen, S.C., Randerson, J.T., 2004. Differences between surface and column atmospheric $\mathrm{CO}_{2}$ and implications for carbon cycle research. J. Geophys. Res. 109. https://doi. org/10.1029/2003JD003968.

Olson, K.R., Morton, L.W., 2012. The impacts of 2011 induced levee breaches on agricultural lands of Mississippi River Valley. J. Soil Water Conserv. 67 (1), 5A-10A. https://doi.org/10.2489/jswc.67.1.5A.

Palmer, P.I., Wilson, E.L., L. Villanueva, G., Liuzzi, G., Feng, L., DiGregorio, A.J., Mao, J., Ott, L., Duncan, B., 2019. Potential improvements in global carbon flux estimates from a network of laser heterodyne radiometer measurements of column carbon dioxide. Atmos. Meas. Tech. 12 (4), 2579-2594. https://doi.org/10.5194/amt-122579-2019.

Plascyk, J.A., 1975. The MK II Fraunhofer line discriminator (FLD-II) for airborne and orbital remote sensing of solar-stimulated luminescence. Opt. Eng. 14 (4), 144339. https://doi.org/10.1117/12.7971842.

Potter, C.S., Randerson, J.T., Field, C.B., Matson, P.A., Vitousek, P.M., Mooney, H.A., Klooster, S.A., 1993. Terrestrial ecosystem production: a process model based on global satellite and surface data. Glob. Biogeochem. Cycl. 7 (4), 811-841. https://doi. org/10.1029/93GB02725.

Prasad, A.K., Chai, L., Singh, R.P., Kafatos, M., 2006. Crop yield estimation model for iowa using remote sensing and surface parameters. Int. J. Appl. Earth Observ. Geoinf. 8 (1), 26-33. https://doi.org/10.1016/j.jag.2005.06.002.

Quaife, T., Cripps, E., 2016. Bayesian analysis of uncertainty in the globcover 2009 land cover product at climate model grid scale. Remote Sens. 8 (4), 314. https://doi.org/ $10.3390 / \mathrm{rs} 8040314$

Rayner, P.J., O'Brien, D.M., 2001. The utility of remotely sensed $\mathrm{CO}_{2}$ concentration data in surface source inversions. Geophys. Res. Lett. 28 (1), 175-178. https://doi.org/10. 1029/2000GL011912.

Rodgers, C.D., 2000. Inverse Methods for Atmospheric Sounding. World Scientifichttps:// doi.org/10.1142/3171.

Sakamoto, T., Gitelson, A.A., Arkebauer, T.J., 2014. Near real-time prediction of US corn yields based on time-series MODIS data. Remote Sens. Environ. 147, 219-231. 
https://doi.org/10.1016/j.rse.2014.03.008.

Shanahan, J.F., Schepers, J.S., Francis, D.D., Varvel, G.E., Wilhelm, W.W., Tringe, J.M., Schlemmer, M.R., Major, D.J., 2001. Use of remote-sensing imagery to estimate corn grain yield. Agron. J. 93 (3), 583-589. https://doi.org/10.2134/agronj2001. 933583x.

Sun, Y., Frankenberg, C., Jung, M., Joiner, J., Guanter, L., Köhler, P., Magney, T., 2018. Overview of solar-induced chlorophyll fluorescence (SIF) from the orbiting carbon observatory-2: retrieval, cross-mission comparison, and global monitoring for GPP. Remote Sens. Environ. 209, 808-823. https://doi.org/10.1016/j.rse.2018.02.016.

Sun, Y., Fu, R., Dickinson, R., Joiner, J., Frankenberg, C., Gu, L., Xia, Y., Fernando, N., 2015. Drought onset mechanisms revealed by satellite solar-induced chlorophyll fluorescence: Insights from two contrasting extreme events. J. Geophys. Res. 120 (11), 2427-2440. https://doi.org/10.1002/2015JG003150.

Suyker, A.E., Verma, S.B., 2012. Gross primary production and ecosystem respiration of irrigated and rainfed maize-soybean cropping systems over 8 years. Agric. Forest Meteorol. 165, 12-24. https://doi.org/10.1016/j.agrformet.2012.05.021.

Takahashi, T., Stewart, C.S., Wanninkhof, R., Sweeney, C., Feely, R., David, W.C., Hales, B., Friederich, G., Chavez, F., Chris, S., Watson, A., Bakker, D., Schuster, U., Metzl, N., Yoshikawa-Inoue, H., Ishii, M., Midorikawa, T., Nojiri, Y., Arne, K., de Baar, H., 2009. Climatological mean and decadal change in surface ocean $\mathrm{pCO}_{2}$, and net sea-air $\mathrm{CO}_{2}$ flux over the global oceans. Deep Sea Res. Part II 56, 554-577. https://doi.org/10. 1016/j.dsr2.2008.12.009.

Trent, T., Boesch, H., Somkuti, P., Scott, N.A., 2018. Observing water vapour in the planetary boundary layer from the short-wave infrared. Remote Sens. 10 (9). https:// doi.org/10.3390/rs10091469.

Twine, T.E., Kucharik, C.J., 2009. Climate impacts on net primary productivity trends in natural and managed ecosystems of the central and eastern united states. Agric. Forest Meteorol. 149 (12), 2143-2161. https://doi.org/10.1016/j.agrformet.2009. 05.012. Environmental Biophysics - Tribute to John Norman

USDA, 2011. Crop Production 2010 Summary (revision). https://usda.library.cornell. edu/

USDA, 2012. Crop Production 2011 Summary. https://usda.library.cornell.edu/

USDA, 2014. Crop Production 2013 Summary. https://usda.library.cornell.edu/

USDA, 2015. Crop Production 2014 Summary (revision). https://usda.library.cornell. edu/
USDA, 2016. Crop Production 2015 Summary. https://usda.library.cornell.edu/ USDA, 2017. Crop Production 2016 Summary. https://usda.library.cornell.edu/

USDA, 2019. Census of Agriculture 2017. https://www.nass.usda.gov/Publications/ AgCensus/2017/index.php\#\#full_report

USDA, 2019. USDA Agricultural Projections to 2028. https://usda.library.cornell.edu/

Wan, Z., 2015. MYD11C2 MODIS/Aqua Land Surface Temperature/Emissivity 8-Day L3 Global 0.05Deg CMG V006. https://doi.org/10.5067/MODIS/MYD11C2.006. Distributed by NASA EOSDIS LP DAAC

van der Werf, G.R., Randerson, J.T., Giglio, L., Collatz, G.J., Mu, M., Kasibhatla, P.S., Morton, D.C., DeFries, R.S., Jin, Y., van Leeuwen, T.T., 2010. Global fire emissions and the contribution of deforestation, savanna, forest, agricultural, and peat fires (1997-2009). Atmos. Chem. Phys. 10 (23), 11707-11735. https://doi.org/10.5194/ acp-10-11707-2010.

Wieneke, S., Burkart, A., Cendrero-Mateo, M.P., Julitta, T., Rossini, M., Schickling, A., Schmidt, M., Rascher, U., 2018. Linking photosynthesis and sun-induced fluorescence at sub-daily to seasonal scales. Remote Sens. Environ. 219, 247-258. https://doi.org/ 10.1016/j.rse.2018.10.019.

Wohlfahrt, G., Gerdel, K., Migliavacca, M., Rotenberg, E., Tatarinov, F., Müller, J., Hammerle, A., Julitta, T., Spielmann, F.M., Yakir, D., 2018. Sun-induced fluorescence and gross primary productivity during a heat wave. Sci. Rep. 8 (1), 14169. https:// doi.org/10.1038/s41598-018-32602-z.

Wolf, S., Keenan, T.F., Fisher, J.B., Baldocchi, D.D., Desai, A.R., Richardson, A.D., Scott, R.L., Law, B.E., Litvak, M.E., Brunsell, N.A., et al., 2016. Warm spring reduced carbon cycle impact of the 2012 US summer drought. Proc. Natl. Acad. Sci. 113 (21), 5880-5885. https://doi.org/10.1073/pnas.1519620113.

Wu, D., Qu, J.J., Hao, X., 2015. Agricultural drought monitoring using MODIS-based drought indices over the USA Corn Belt. Int. J. Remote Sens. 36 (21), 5403-5425. https://doi.org/10.1080/01431161.2015.1093190.

Yokota, T., Yoshida, Y., Eguchi, N., Ota, Y., Tanaka, T., Watanabe, H., Maksyutov, S., 2009. Global concentrations of $\mathrm{CO}_{2}$ and $\mathrm{CH}_{4}$ retrieved from GOSAT: First preliminary results. Sola 5, 160-163. https://doi.org/10.2151/sola.2009-041.

Zhong, L., Yu, L., Li, X., Hu, L., Gong, P., 2016. Rapid corn and soybean mapping in US Corn Belt and neighboring areas. Sci. Rep. 6, 36240. https://doi.org/10.1038/ srep36240. 